\section{Don't let witch hunts taint investigations}

Donald Kornfeld and Sandra

Titus argue that misconduct should be considered when investigating irreproducible research (Nature 537, 29-30; 2016). In my view, this premise of 'guilty until proved innocent' risks turning a scholarly investigation into a witch hunt.

Distinguishing poorly designed research from faked data is hard, but it is generally more difficult to prove misconduct than to identify the cause of irreproducibility. Moreover, investigating bad science costs less than examining misconduct (in terms of money, time, careers and so on). One estimate put the direct cost of a misconduct enquiry at US $\$ 525,000$

(A. M. Michalek et al. PLoS Med. 7, e1000318; 2010).

The authors assert that the US National Institutes of Health's (NIH) training mandate for responsible conduct of research failed to reduce misconduct. Perusing research on the rate of misconduct, I find estimates that span several orders of magnitude, so it is unclear whether misconduct is or has been rising or falling. Thus, we cannot say what effect the NIH training scheme has had.

The damage caused to the scientific record by publishing sloppy, plagiarized or fabricated research is ultimately the same. Kenneth Pimple Indiana University, Bloomington, USA. pimple@indiana.edu

\section{University on the rise without PhD students}

California State University in Northridge (CSUN) is ranked 24th in the latest Nature Index of the 25 North American institutions classed as 'Rising stars' (see go.nature.com/2dfvirb). Of these, CSUN has the greatest percentage increase in publications in 2012-15 in high-impact journals (up by $190.61 \%)$. As professor emeritus at CSUN, my view is that the rise is attributable to the university's unusual research model.

The university does not offer any PhD degrees. Instead, science undergraduates and master's students work alongside exceptional faculty members, who train and mentor them in research. The faculty includes 28 prestigious members hired over the past decade. The dean of the science college, Jerry Stinner, backed by the university chairs, president and provost, organized CSUN funding to recruit and support them. This support included comprehensive packages of research equipment and supplies, specific laboratory renovations and a reduced teaching load while they set up their labs.

Steve Oppenheimer California State University, Northridge, California, USA.

steven.oppenheimer@csun.edu

\section{Hasten end of dated fossil-fuel subsidies}

Nations at last month's G20 summit in China reaffirmed their 2009 commitment to phase out fossil-fuel subsidies, echoing a call from almost two decades ago to end subsidies that are "adverse in the long run to both the economy and the environment" (N. Myers Nature 392, 327-328; 1998).

Similar 'perverse' subsidies continue to encourage logging of the few remaining pockets of oldgrowth forest in western Canada and overfishing in the high seas. Yet the fossil-fuel industry receives the largest subsidy of all, estimated by the International Monetary Fund (IMF) last year at US $\$ 1,000$ annually for every citizen in the G20 group. Most of this is provided by countries with energy taxes that are too low to cover the adverse effects of fossilfuel consumption on human health and the environment (go.nature.com/2dbs2zf).
The IMF also estimates that eliminating fossil-fuel subsidies would cut global carbon dioxide emissions by more than $20 \%$ and raise government revenues by $\$ 2.9$ trillion (or $3.6 \%$ of global gross domestic product). Such a step would save up to $\$ 93$ per tonne of greenhousegas emissions removed (see go.nature.com/2dowcw).

These sums alone would fund climate adaptation and the protection of imperilled global biodiversity for the next 30 years (D. P. McCarthy et al. Science 338, 946-949; 2012). The money would also boost development of renewable energy sources and domestic support for a low-

carbon economy.

Tara Martin University of British Columbia, Vancouver, Canada. tara.martin@ubc.ca

\section{Are farmed fish just for the wealthy?}

Christopher Golden and colleagues argue that farmed fish contribute little to global food security because they are "mostly exported to the wealthy countries of Europe and North America" (Nature 534, 317-320; 2016). In fact, more than $90 \%$ of farmed fish produced in China, India, Indonesia, Bangladesh, Egypt, the Philippines and Myanmar - some of the world's largest aquaculture-producing developing countries - remains in domestic markets (see go.nature.com/2dqwwh).

Aquaculture products are more accessible to the poor in many developing nations than ever before (K. A. Toufique and B. Belton World Dev. 64, 609-620; 2014). And the aquaculture boom of the past two decades has stabilized world fish prices (S. Tveterås et al. PLoS ONE 7, e36731; 2012).

The realities of the supply and demand of aquaculture products mean that these now complement capture fisheries for global food and nutrition security. Ben Belton Michigan State
University, East Lansing, USA. Simon R. Bush Wageningen University, the Netherlands. David C. Little University of Stirling, UK.

beltonbe@msu.edu

Christopher Golden et al. reply - Our argument is that most farmed fish are not reaching nutritionally vulnerable people in the low-income, food-deficit countries of sub-Saharan Africa and the Pacific islands (Nature 534, 317-320; 2016). In those nations, fish is a traditional food source that comes primarily from capture fisheries, including subsistence harvests (M. M. Dey et al. Mar. Policy 67, 156-163; 2016). Domestic consumption and import of aquaculture products are still relatively insignificant (see go.nature.com/2dinzuc).

In such places, aquaculture policy interventions need to be optimized for nutritional value and distribution to food-insecure populations. This could be achieved through appropriate regulations and market instruments (such as tax incentives or subsidies) and public-health campaigns, in close alliance with conservation strategies for sustainable fisheries.

Harvard T. H. Chan School of Public Health, Cambridge, Massachusetts, USA. golden@hsph.harvard.edu

\section{CORRECTIONS}

The Outlook article 'Industrial strength' (Nature 537, S57S59; 2016) incorrectly stated that the 1999 trial at the University of Pennsylvania was based on a retrovirus; it was in fact based on an adenovirus.

Also, the Outlook Q\&A 'Illuminated Universe' (Nature 537, S205; 2016) incorrectly gave the amount of dark energy in a cubic metre of space as 10-27 kilograms instead of $10^{-27}$ kilograms. 